\title{
Ensino de Física Moderna: perspectivas e desafios sob o olhar de alguns professores de Física do Ensino Médio
}

Modern Physics Teaching: Prospects and challenges in the view of some high school physics teachers

\author{
A. C. Santos*; S. D. Nascimento; D. N. Souza \\ Programa de Pós-Graduação em Ensino de Ciências e Matemática, Universidade Federal de Sergipe, 49.100-00, São \\ Cristóvão-Sergipe, Brasil \\ *anacaciapjmp_gloria@hotmail.com
}

(Recebido em 22 de fevereiro de 2016; aceito em 23 de junho de 2016)

\begin{abstract}
Neste artigo são discutidos os resultados de uma pesquisa realizada com alguns professores de Física de escolas públicas e privadas do município de Aracaju sobre a importância de se introduzir a Física Moderna no Ensino Médio, como também sobre as facilidades e dificuldades que os docentes têm para lecionar os conteúdos referentes a essa "nova" Física. No decorrer de todo o artigo são discutidas as questões referentes à necessidade de se ensinar conteúdos da Física pós Newton, para que os discentes percebam e vivenciem essa Física no cotidiano deles. Os resultados mostram que a maioria dos docentes entrevistados reconhecem a importância da Física Moderna, mas não abordam em suas aulas por diversos fatores, sendo o Exame Nacional do Ensino Médio (Enem) o principal deles. Ficou evidente que tanto o currículo do Ensino Médio bem como o Enem não estimulam a inserção dos tópicos de Física Moderna nessa etapa da escolar.

Palavras-chave: Ensino, Física Moderna, Professores
\end{abstract}

This article discusses the results of a survey of some physics teachers from public and private schools in the city of Aracaju on the importance of introducing modern physics in high school, but also about the facilities and difficulties that teachers have to teach content relating to this "new" physics. During the entire article discusses issues relating to the need for teaching content of the post Newton Physics, so that students understand and to experience this physics in their everyday lives. The results show that most respondents teachers recognize the importance of modern physics but do not deal in their classes by several factors, being the Brazilian National Secondary Education Examination (Enem) the main one. It was evident that both the high school curriculum and the ENEM not stimulate the inclusion of the topics of Modern Physics that the school stage.

Palabras clave: Educación, Física Moderna, Maestros

\section{INTRODUÇÃO}

A disciplina Física é tradicionalmente compreendida pela maioria dos alunos como desinteressante, por trazer nos conteúdos muitos cálculos matemáticos, que, aparentemente, não têm serventia para as atividades práticas no cotidiano desses alunos [1]. Por isso, pode-se considerar que, para alguns conteúdos da disciplina, é comum eles fazerem aos seus professores questionamentos como: para que serve esse assunto? Irei usar esse cálculo em quê? Para que estudar Física se não irei precisar dela lá fora? Esses questionamentos podem resultar da forma como são ensinados para eles os conteúdos de Física ou mesmo da escolha dos conteúdos. Mas é importante considerar como verdade que muitos dos estudantes da educação básica não encontrarem aplicabilidade da Física ensinada na escola, o que prejudica no entendimento da importância dessa ciência para a evolução tecnológica, inclusive da que vivenciamos na atualidade.

Diante dessa realidade, fica cada vez mais evidente a necessidade de o professor de Física do Ensino Médio mostrar nas aulas exemplos presentes no cotidiano dos educandos relacionados à Física, para que eles possam perceber a importância e a finalidade de se estudar essa ciência, que é fundamental para o entendimento do mundo que os cerca.

Com o mundo cada vez mais tecnológico e com, atualmente, uma maior possibilidade de acesso aos recursos derivados desse avanço, em especial pelos jovens, é de se considerar que seja cada vez mais necessária a inserção dos tópicos de Física Moderna e Contemporânea (FMC) no Ensino 
Médio. Afinal, o conhecimento dessa Física poderá despertar nos alunos um olhar mais atento e curioso sobre os objetos que estão ao seu redor, como os celulares, notebooks, tablets, dentre outros.

No início da década passada Ostermann e Moreira (2000)[2] já traziam a preocupação de ser comum para os estudantes ouvirem falar de Física Quântica, de buraco negro, do big bang, radiação e Física Nuclear nos filmes que assistem, mas nunca em sala de aula. Infelizmente, nos dias atuais a Física Moderna e Contemporânea no Brasil ainda não é tão difundida na escola básica, o conteúdo ensinado continua abordando quase sempre somente a Física Clássica. Com isso, pode-se entender que os temas levantados por esses autores continuam sendo pouco discutidos no Ensino Médio. Embora, possam ser observados na literatura científica muitos textos com discussões relacionadas com a essa necessidade de inserção ou com relatos de experiências voltadas para a abordagem de conteúdos de FMC, mesmo que sejam pontuais. Um exemplo de experiência bem atual é relatada por Barcellos e Guerra (2015)[3], que buscaram auxiliar um professor de Física na busca de subsídios para abordar conteúdos de FMC em sala de aula de nível médio.

De acordo com Parâmetros Curriculares Nacionais Ensino Médio (PCNEM), a Física deve ser reconhecida como um processo cuja construção ocorreu ao longo da história da humanidade, impregnada de contribuições culturais, econômicas e sociais, que vem resultando no desenvolvimento de diferentes tecnologias e, por sua vez, por elas impulsionado [4].

O objeto do estudo aqui apresentado é a realização de uma pesquisa com professores de Física do Ensino Médio, tanto da rede particular de ensino quanto da rede pública no município de Aracaju, tendo como objetivo investigar a opinião de alguns desses professores sobre a inserção de tópicos de Física Moderna e Contemporânea no Ensino Médio, ou seja, nas aulas que eles ministram. Almeja-se também discutir sobre as facilidades e dificuldades que eles têm ao ensinar essa Física que vem se desenvolvendo nos últimos séculos. Por simplicidade, os questionamentos feitos trataram somente de Física Moderna e Contemporânea.

\section{MATERIAL E MÉTODOS}

O estudo aqui relatado baseou-se na aplicação de um questionário composto de oito questões a seis professores de Física do Ensino Médio, sendo três deles da rede pública e três da rede particular de ensino básico do Município de Aracaju. Os questionários foram aplicados em maio de 2015. Por motivo de ética, não serão divulgados os nomes dos participantes e nem as instituições que eles lecionam. Todos os entrevistados são licenciados em Física, sem título de pós-graduação.

$\mathrm{Na}$ preparação dos questionários procurou-se elaborar perguntas que colaborassem com a finalidade com trabalho, que mostrasse a importância que os professores dão a Física Moderna, como também as dificuldades e as facilidades que os docentes tem em abordar esse conteúdo em sala de aula.

Visando alcançar o objetivo, optou-se por uma pesquisa qualitativa, por possibilitar a compreensão da realidade, sendo uma fonte de subsídios para uma investigação científica no âmbito do cotidiano escolar [5]. Adotamos procedimentos científicos que foram seguidos durante o curso desta pesquisa, que consistiram essencialmente em: revisão da literatura e aplicação de questionários. Entendemos que esses instrumentos metodológicos foram adequados para a aproximação ao objeto de estudo. Nossa análise consistiu em descrição dos depoimentos coletados e discussão dos dados empíricos, a partir do depoimento dos docentes que lecionam a disciplina de Física nas escolas supramencionadas.

\section{RESULTADOS E DISCUSSÃO}

A seguir são apresentadas as perguntas que nortearam a pesquisa, juntamente com as respectivas análises das respostas obtidas.

\section{1 - Você leciona em quais séries?}

Os professores da rede particular de ensino lecionam no $9^{\circ}$ ano do ensino fundamental e nas $1^{\text {a }}$, $2^{\mathrm{a}}$ e $3^{\mathrm{a}}$ séries do ensino médio, sendo que um deles também ensina em classes de Educação de 
Jovens e Adultos (EJA) em uma escola pública. Dois professores da rede pública estavam lecionando somente no Ensino Médio e um no Ensino Médio e em um curso pré-vestibular ofertado pela Secretaria de Estado da Educação Sergipe.

2 - Você acha importante abordar a história da Física no Ensino Médio? Utiliza dessa abordagem em suas aulas?

A maioria dos professores (5) respondeu que sim, embora abordem a história da Física somente para introduzir os conteúdos da disciplina, conforme pode-se observar na transcrição das respostas a seguir.

Importante, sim. Utilizo sempre na parte introdutória do tema a ser estudado. (Professor 1)

Sim. A história da Física deixa os alunos mais instigados para o aprendizado. (Professor 2)

Somente um professor informou que não usa a história da Física nas aulas que ministra. Esse professor acredita que o ENEM (Exame Nacional do Ensino Médio) eliminou a importância dessa abordagem.

Acredito que ela já foi importante antes do ENEM se tornar o principal meio para ter acesso às universidades. Eu particularmente não uso. (Professor 3)

Essa afirmação do professor 3 é de fato constatada, e inclusive tem sido motivo de reflexão de pesquisadores da atualidade, a exemplo de José et al. (2014)[6] e Silveira, Barbosa e Silva (2015)[7].

3- Você já abordou algum Tópico de Física Moderna em suas aulas? Caso sim, quais já abordou? Caso não, por que nunca abordou? A que você atribui a sua escolha?

Dois professores responderam que sim, sendo que um afirmou que aborda com mais abrangência e o outro somente um tópico de Física Moderna.

Sim, leciono na segunda série ideias básicas da Física Quântica, Efeito Fotoelétrico, Teoria da Relatividade, Princípios da Relatividade Especial, Energia Relativística, Radiação de Corpo Negro, O Princípio de incerteza de Heisenberg, Reações Nucleares (Fissão e fusão), Poços de Energia Potencial. (Professor 1).

Sim, Relatividade geral. (Professor 4)

Quatro professores responderam que não; um atribuiu à necessidade de realização de experimentos; dois atribuíram à falta de tempo e outro porque não é cobrado no ENEM.

Não, mas passo trabalho em cima dos assuntos mais importantes (Efeito fotoelétrico e espectro eletromagnético); não abordo de fato devido ao Enem. Não fui ainda pelo caminho da Física Moderna, pois exige situações práticas, experimentos simples, junto com a habilidade e competência do aluno para relacionar isso com a Física. (Professor 3)

Os colégios em que ensino utilizam um sistema chamado Dom Bosco, que não traz o tópico de Física moderna. (Professor 2)

Não, devido ao tempo ser corrido, são somente duas aulas semanais e mal dá para ensinar a Física Clássica. (Professor 5)

4- O livro didático adotado pela escola que você trabalha traz algum tópico de Física Moderna? Se sim, quais tópicos?

Somente um professor falou que o livro didático não aborda, os demais informaram que sim. Ele traz os seguintes tópicos: Importância da Física Moderna, Introdução à Teoria da Relatividade, Princípios Relatividade Especial, Energia Relativística, O Nascimento da Física Quântica, Ideias Básicas da Física Quântica, 
Desenvolvimento Posterior da Física Quântica, Perspectivas da Física Moderna, Reações Nucleares Fissão e fusão e Poços de Energia Potencial. (Professor 1) Sim, uma leve abordagem de todos os tópicos de Física moderna. (Professor 4) Sim, Relatividade Geral e Quântica. (Professor 3)

Não aborda, mas deveria abordar porque os alicerces da Física moderna estão apoiados nas teorias de Einstein, Planck, entre outros, e é interessante que os alunos compreendam como funciona essa "nova Física". (Professor 2)

Sim, todos os conteúdos de Física quântica (parte introdutória). (Professor 5)

Sim, Relatividade Geral, Quântica, Efeito Fotoelétrico. (Professor 6)

\section{5- O ENEM tem influenciado nessa escolha? Por quê?}

Todos os entrevistados informaram que sim, e que devido a isso a Física Moderna acaba ficando de lado no planejamento dos conteúdos que são abordados em sala da aula, pois o ENEM não traz questões referentes aos conteúdos relacionados a essa parte da Física.

Sim, pois opto por focar em assuntos possíveis de serem abordados no ENEM. (Professor 1)

Sim, porque ela aborda a Física mais simples, do nosso cotidiano. E temos que seguir o sistema atual. (Professor 3)

Sim, eu uso o ENEM como base para o planejamento de minhas aulas, em outras palavras, trabalho os assuntos cobrados no ENEM. (Professor 4)

Creio que sim, infelizmente o ENEM não cobrou nenhuma questão de Física moderna, por conta disso as escolas e os livros deixaram esse assunto esquecido. (Professor 2)

Acredito que sim, pois trabalho as questões do ENEM em sala de aula. (Professor 5)

Sim, somos obrigados a trabalhar de acordo com o ENEM. (Professor 6).

Na análise que José et al. (2014) [6] realizaram sobre as questões de Física das edições do ENEM de 2009 a 2012, os autores mostram que apesar do ENEM ressaltar questões contextualizadas e interdisciplinares que fazem parte do cotidiano dos alunos, a Física Moderna e Contemporânea ainda não é mencionada. Assim, esse exame tem privilegiado um currículo totalmente voltado para Física Clássica. Essa realidade acaba influenciando na prática pedagógica dos docentes e na grade curricular das instituições de Ensino. Devemos aqui chamar a atenção para os PCNEM [4] e nos PCN+[8], nos quais a inserção da Física Moderna entre os conteúdos abordados no Ensino Médio já era incentivada e considerada indispensável. Para os PCN+[8].

Alguns aspectos da chamada Física Moderna serão indispensáveis para permitir aos jovens adquirir uma compreensão mais abrangente sobre como se constitui a matéria, de forma a que tenham contato com diferentes e novos materiais, cristais líquidos e lasers presentes nos utensílios tecnológicos, ou com o desenvolvimento da eletrônica, dos circuitos integrados e dos microprocessadores. A compreensão dos modelos para a constituição da matéria deve, ainda, incluir as interações no núcleo dos átomos e os modelos que a ciência hoje propõe para um mundo povoado de partículas. [p.70]

Com base nisso, podemos perceber que existe uma incoerência entre o que o ENEM aborda e o que os documentos PCNEM[4] e PCN+[8] pregam, e isso acaba por definir um currículo de Física para o Ensino Médio cada dia mais fragmentado e distante da realidade atual dos alunos, o que corrobora para que a maioria dos docentes não mencione ou utilize em suas aulas os conteúdos de Física Moderna e Contemporânea.

6 - Quais as facilidades e dificuldades didáticas você tem para abordar Física Moderna?

Facilidades - Temas mais atuais e que despertam interesse dos alunos. 
Dificuldades - Poucos materiais didáticos disponíveis no mercado que sejam voltados para o Ensino Médio e que aprofundem no estudo dos temas relacionados à Física Moderna. (Professor 1)

São assuntos complexos, de difícil entendimento, que mergulham numa região microscópica, e considerando que muitas vezes os alunos já possuem a dificuldade de entender a Física do nosso cotidiano, pode piorar no mundo quântico. (Professor 3)

Eu acho que é mais dificuldades, pois o tempo é muito curto para trabalhar todos os assuntos durante o ano. (Professor 4)

Facilidades: explicar a teoria. Dificuldades: fazer com que os alunos entendam os cálculos. (Professor 2)

A facilidade é que todo o âmbito de novas tecnologias está relacionado com Física Moderna. A dificuldade pode estar relacionada com o formalismo matemático, que não é simples. (Professor 5)

Facilidade por ser uma Física das tecnologias. Dificuldades em encontrar materiais para o Ensino Médio com uma linguagem acessível e de fácil compreensão. (Professor 6)

Percebe-se desse modo, que os professores já sinalizam a necessidade de reformulação do livro didático e do currículo escolar, pois alguns livros não abordam de fato a fica moderna, muitas trazem apenas uma introdução do assunto e não aprofunda. Os professores na verdade estão preocupados com o formalismo matemático que vem nos livros e em momento algum eles falaram sobre a importância da teoria e o quanto ela é rica em informação, os educadores deixaram claro que a maioria dos livros que retrata essa temática são de nível superior e sua linguagem é complicada e não é acessível para o aluno do Ensino Médio. Siqueira e Pietroloca (2005)[10] em seus estudos sobre a inserção da FMC enfatiza que:

Há aproximadamente duas décadas, vem sendo discutido a relevância da inserção da FMC no Ensino Médio nas escolas do Brasil, chegando ao consenso de que é possível aplicá-la. No entanto, essa discussão se restringe aos argumentos "para que" e "por que" deve ser ensinado, deixando de lado o "como fazer ". Esses argumentos ainda foram reforçados, em 1996, quando a LDB, trouxe como um dos seus objetivos a necessidade de renovação curricular, visando os aspectos mais modernos da ciência, reforçando assim, a necessidade de atualização e renovação do currículo de Física no E.M.

A renovação da grade curricular vem sendo discutida há muito tempo, acredita-se que essa mudança de grade poderá contribuir e fortalecer a inserção da FMC no Ensino Médio, pois dessa maneira as escolas serão obrigadas a trabalharem com essa "Física" tão atual e acessível para os alunos e novos materiais didáticos poderão surgir no sistema educacional com uma linguagem menos rebuscadas para que discentes do nível Médio possam compreender de uma maneira mais fácil a FMC.

7- Você acha que os alunos iriam se interessar por Física Moderna, caso fosse abordada nas aulas? Por quê?

Dois professores responderam que sim, mas não justificaram suas respostas, os demais justificaram.

Acredito que se interessariam por pouquíssimas coisas, devido à complexidade dos assuntos. (Professor 3)

Como Física é uma disciplina menos amada pelos alunos, acho meio difícil que eles se interessarem, salvo alguns que se destacam. (Professor 4)

Sim, por ser um conteúdo novo e revolucionador. (Professor 2)

Sim. É uma disciplina bem interessante. (Professor 5)

Segundo Jesus e Diniz (2014) [9] "a FMC pode ser abordada no Ensino Médio, desde que haja um cuidado especial para não caracterizá-la junto aos alunos como mais um tema distante de sua 
realidade e cujo estudo meramente expositivo pode se tornar enfadonho." Os autores salientam que é possível introduzir a FMC no Ensino Médio, mas cabe ao professor procurar maneiras viáveis de inseri-la e mostrar que a FMC está intimamente ligada com o cotidiano dos alunos, dessa maneira a "nova Física" poderá interessar os alunos, pois ela irá sair da abstração e se tornará algo concreto em suas vidas.

8- Quais os tópicos mais importantes de Física Moderna para você?? Por quê?

Todos os assuntos são importantes, pois cada um tem sua parcela de contribuição através dos seus conceitos e aplicações, no entendimento do que efetivamente acontece no mundo cotidiano. (Professor 1)

Efeito Fotoelétrico e espectro eletromagnético. Porque acredito que a aplicabilidade desses assuntos no nosso dia a dia é mais visível. (Professor 3) Como Física é uma disciplina menos amada pelos alunos, acho meio difícil que eles se interessarem, salvo alguns que se destacam. (Professor 4)

A teoria da Relatividade Geral, pois nessa teoria Einstein mostra alguns erros elou fracassos que a mecânica Newtoniana não tinha percebido. (Professor 2) Efeito fotoelétrico, radiação de corpo negro, princípio da incerteza etc. são conteúdos iniciais, que envolvem o surgimento da mecânica quântica. (Professor 5)

Efeito Fotoelétrico, Física Quântica, Física Nuclear. (Professor 6)

Um aspecto muito relevante aparece nas respostas dos professores: a necessidade de formação. Alguns dos entrevistados têm recursos para trabalhar, mas não acham viável abordar esses temas em sala de aula. Talvez isso aconteça devido à falta de informação adequada sobre a importância dessa Física no Ensino Médio. Vale ressaltar que os entrevistados têm poucos anos de formados e, consequentemente, poucos anos em sala de aula. Ficou evidente que a maioria dos professores só utilizam o livro de didático em sua prática pedagógica, não fazendo uso de materiais como filmes, vídeos, leituras de artigos científicos ou visitas a casas de ciências.

\section{CONCLUSÃO}

O presente trabalho pretendeu mostrar os aspectos ligados a inserção de Física Moderna no Ensino médio sob o olhar de alguns professores, como também compreender as facilidades e dificuldades que eles têm em inseri-la nas suas aulas, a partir da ótica de alguns professores de escolas privadas e públicas do município de Aracaju, SE. As respostas dos professores entrevistados, tanto os da rede pública quanto os da rede privada de ensino, não foram muito discordantes.

As opiniões explicitadas pelos docentes nos permitiram identificar alguns fatores que devem ser levados em considerações a respeito da inserção de Física Moderna, principalmente sobre os porquês de eles lecionarem ou não em suas aulas. É notório nas falas dos entrevistados que a maior dificuldade em ensinar está relacionada a carga horária, falta de material disponível para o Ensino Médio e ao fato das escolas terem um currículo voltado para o Enem.

As facilidades demonstradas pelos entrevistados se deram ao fato da relação que a FMC tem com as novas tecnologias e seu uso no dia a dia. Mais da metade dos professores consideram importante a Física Moderna, mas precisa de materiais adequados para trabalhar esse tema em sala de aula. $\mathrm{O}$ que que nos chamou atenção foi o fato deles não reclamarem de formação, nenhum professor falou que não ensinava ou abordava a FMC em suas aulas porque não se sentia preparado ou porque não tinha a formação adequada para lecioná-la.

Percebe-se que essa "nova" Física é um tema que ainda precisa ser amplamente discutido, que a falta de preparação, por partes dos professores, para a compreensão da importância de inseri-la no Ensino médio ainda é grande. Se o ENEM abordasse questões relacionada à Física Moderna e Contemporânea, possivelmente auxiliaria no processo de inserção dessa Física tão presente no cotidiano, pois motivaria os docentes a abordarem em sala de aula. 


\section{REFERÊNCIAS BIBLIOGRÁFICAS}

1. Oliveira WD. Uma proposta de plano de curso para conteúdos de Física em Nível Médio, através do trabalho articulado entre professores de Física e de Matemática, em situação de coordenação pedagógica, visando a Aprendizagem Significativa. Dissertação de Mestrado. Programa de Pós-Graduação em Ensino de Ciências da Universidade de Brasília, 2012.

2. Ostemann F; Moreira MA. Física Contemporânea em la escuela secundaria: una experiência en el aula involucrando formación de profesores. Enseñ. Cienc. 2000 Dez;18(3):391-404

3. Barcellos M.; Guerra A. Inovação curricular e Física moderna: da prescrição à prática. Ens. Pesq. Educ. Ciênc. 2015 Mai;17(2), 329-350. doi.org/10.1590/1983-21172015170203

4. Brasil. Ministério da Educação, Secretaria da Educação Média e Tecnológica. Parâmetros Curriculares Nacionais do Ensino Médio. Brasília: Ministério da Educação, 2000.

5. André M E A. Etnografia da prática escolar. 5ed. Campinas, SP: Papirus, 2000.

6. José WD; Braga GR.; Nascimento AQB.; Bastos F P. ENEM, temas estruturadores e conceitos unificados no ensino de Física. Ens. Pesq. Educ. Ciênc, 2014 Set;16(3), 171-188.doi.org/10.1590/198321172014160308

7. Silveira F L.; Barbosa M C B.; Silva R. Exame Nacional do Ensino Médio (ENEM): Uma análise crítica. Rer. Bras. Ensino Fís. 2015 37(1):1101 doi.org/10.1590/S1806-11173710001

8. Brasil, Ministério da Educação e Cultura- Secretaria de Educação Básica. Orientações Educacionais Complementares aos Parâmetros Curriculares Nacionais do Ensino Médio, 2002.

9. Jesus MA; Diniz, JB. O estudo da vida e obra de grandes nomes da Física Moderna e Contemporânea através da produção de vídeos com a técnica Draw My Life. South American Journal of Basic Education a, Tecnical and Technological. 2014 Set 1(1): 72-80

10. 10.Siqueira M.; Pietrocola M. A Transposição Didática Aplicada a Teoria Contemporânea: A Física de Partículas Elementares no Ensino Médio. X Encontro Nacional de Pesquisa em Ensino de Física, 2006 